\title{
EVALUATION OF HEALTH CARE AND HUSBANDRY SYSTEM OF CALVES AT BUFFALO FARMS IN SOUTHERN BANGLADESH
}

\author{
A. K. Talukder ${ }^{* 1}$, M. A. Rahman ${ }^{2}$, M. A. Islam ${ }^{3}$, M. T. Islam ${ }^{4}$, A. S. M. Selim ${ }^{5}$ A. \\ K. Paul ${ }^{6}$ and M. A. Rahman ${ }^{6}$ \\ Department of Gynecology, Obstetrics and Reproductive Health \\ Bangabandhu Sheikh Mujibur Rahman Agricultural University, Gazipur 1706, Bangladesh
}

\begin{abstract}
Calves with optimum health play a crucial role for sustainability of the dairy farms. This study was conducted to evaluate the present status of calf health care and husbandry system on 140 buffalo farms in southern Bangladesh. The data were collected during farm visit and recorded in prepared questionnaire. The results of the present study revealed that significantly lower number of farms (15.0\%) had calves with good body condition $(p<0.05)$ during farm visit. Navel cord disinfection to the newly born calves was not practiced in all these farms. Colostrum was fed to calves soon after birth in significantly lower number $(4.3 \%)$ of farms $(p<0.05)$. Furthermore, $13.6 \%$ farmers dewormed their buffalo calves $(p<0.05)$ and calves in $11.4 \%$ farms were vaccinated against anthrax and foot and mouth disease $(p<0.05)$. Sick calves were treated by buffalo owner themselves in significantly higher proportion of buffalo farms $(59.3 \%)$ compared with treated by veterinarian $(12.9 \%)$ and quack $(27.8 \%)(p<0.05)$. Overall, the buffalo calf mortality was recorded $14.5 \%$ of which higher mortality (74.5\%) was observed in first three months of age in comparison to other age groups. Moreover, the number of calves died was affected by herd size in the farms $\left(R^{2}=0.938, p<0.001\right)$. The helminthiasis $(20.3 \%)$ was identified as most prevalent disease in buffalo calves followed by malnutrition (13.2\%), indigestion (12.4\%) and navel ill $(9.3 \%)$. It can be concluded that health care and management system of buffalo calves in these dairies are extremely unsatisfactory and buffalo farmers need proper education and training about scientific knowledge of calf rearing practice.
\end{abstract}

\footnotetext{
* Corresponding author email anupbau@gmail.com

${ }^{1}$ Department of Gynecology, Obstetrics and Reproductive Health, BSMRAU, Gazipur-1706, Bangladesh

${ }^{2}$ Department of Surgery and Radiology, BSMRAU, Gazipur-1706, Bangladesh

${ }^{3}$ Department of Medicine, BSMRAU, Gazipur 1706, Bangladesh

${ }^{4}$ Department of Pathobiology, BSMRAU, Gazipur-1706, Bangladesh

${ }^{5}$ Department of Animal Science and Nutrition, BSMRAU, Gazipur-1706, Bangladesh

${ }^{6}$ Department of Medicine, Surgery and Obstetrics, Faculty of Animal Science and Veterinary Medicine, Patuakhali

Science and Technology University, Babugonj, Barisal-8210, Bangladesh
}

Received: 23.08.2015 
Keywords: Buffalo calf, health care, husbandry system, southern

Bangladesh

\section{INTRODUCTION}

One emerging trend in Bangladesh is increasing number of the dairy farms. This is because; increased mechanization of crop production has resulted in a gradual reduction in the need for draft animals (Shamsuddin et al., 2006). Bangladesh has about 1.39 millions buffalo (Osmani, 2012); those are found in the BramhaputraJamuna flood plain of central Bangladesh and Ganges-Meghna flood-plain of southern Bangladesh. Buffaloes are mainly raised under an extensive system in the coastal and hilly areas where large scale pasture land and enough green forage are available. Other than those, rests are mostly raised under a semi-intensive system on plane and marshy land where there is limited pasture land. The buffalo farming has now got popularity because of their outstanding productivity performance in comparison to that of cows in Bangladesh. It is reported that farmers' yearly net income per lactating buffalo (US\$ $361 \pm 147$ ) is eight times more than that from an indigenous lactating cow (US\$ 47 \pm 25 ) under smallholder dairy farming system at Kanihari union of Mymensingh district in Bangladesh (Talukder et al., 2008).

Calves are the asset of buffalo farms which first replace the culled cows as dairy replacement heifers in farm and finally go for production. Health management and proper nutrition to the calves are considered as two important aspects of the calf rearing practice (Tiwari et al., 2007). Many research studies have revealed the poor condition of calves in the buffalo farms wherein the farmers were not much aware about the scientific management practices of calf (Khan et al., 2007; Tiwari et al., 2007; Maousami et al., 2013; Matondi et al., 2014). Apart from that, higher calf mortality is a major impediment to the buffalo farms (Tiwari et al., 2003). Therefore, it appears that the proper veterinary health care and husbandry practices of calves in the buffalo farms are essential for sustainable development of the dairying in any country.

Although, buffalo farming has been an indispensible part for the livelihoods of buffalo owners in southern region of Bangladesh; however, there is a dearth of information available on present status of buffalo calf health care and management practices in these farms. Therefore, this study was conducted to evaluate the present health care and management system of calves at the buffalo farms in southern region of Bangladesh.

\section{MATERIALS AND METHODS}

\section{Study location and period}

This study was conducted in four districts of southern Bangladesh (Barisal Division) namely Barisal (Bakergonj Upazilla), Patuakhali (Galachipa and Bauphal 
Upazilla), Jhalokati (Nolchiti Upazilla) and Bhola (Char-fassion Upazilla) during the period from July 2011 to June 2012.

\section{Data collection}

One hundred 40 buffalo farms (35 from each district) were included in this study. A questionnaire was developed to record the relevant information on the selected parameters. Interview with buffalo owners was made for collection of data during visit of these farms. The major parameters observed in this study include calf population, general body condition of calves at farms, health care system (navel care, deworming practice, vaccination and treatment policy), husbandry practices (colostrum feeding, milk feeding, housing and bedding), calf mortality and prevalence of diseases in calves.

\section{Data analysis}

Collected data were entered into Microsoft Excel Worksheet 2007. Descriptive statistical analysis was carried out using Statistical Package for Social Sciences SPSS version 14.0. One way ANOVA analysis was applied to compare the data among the groups. Linear regression analysis was carried out to see the effect of farm size on number of calves died (absolute calf mortality).

\section{Buffalo population}

\section{RESULTS AND DISCUSSION}

The number of buffalo population per farm is shown in table 1. Barisal had higher number of buffaloes constituting 48.5 per farm with 18.4 lactating buffaloes and 15.7 buffalo calves. In Patuakhali, number of buffaloes was 38.9 per farm having 13.7 lactating cows and 11.7 calves. The number of buffaloes, lactating cows and calves were 22.9, 6.7 and 5.7 per farm, respectively in Bhola District. Buffalo population was found lower in number in Jhalokati compared to other Districts (Table 1). The low population of buffaloes in Bhola and Jhalokati Districts might be due to limited pasture land, high price of concentrate and low access to sell the milk in these areas. The buffaloes were reared in loose house system and lactating cows were milked two times daily with their calves used for stimulating milk letdown. Calves survived on residual milk after the hand milking. Control weaning was not practiced. The buffaloes were fed mainly on pasture land with limited rice straw, cutand-carry grasses and milling by-products as concentrate (crashed rice and/or sometimes mustard oil cake).

\section{Health condition of buffalo calves}

The general body condition and appearance of buffalo calves found in buffalo farms is presented in table 2. Calves having good body condition were observed only in $15.0 \%$ farms during farm visit. Calves with average body condition were observed in $50.0 \%$ farms, while in $35.0 \%$ farms, calves were weak and emaciated and this difference is statistically significant $(\mathrm{p}<0.05)$. Restricted milk 
feeding, high prevalence of endoparasitic diseases and overall faulty management system might lead to higher number of unhealthy calves in these farms.

\section{Health care to calves in buffalo farm}

Navel health care practice of newborn buffalo calves is figured out in this study. No buffalo owners did cut and disinfect the naval cord after birth of calves (Table 3a). Similar findings have been reported by Kumar (2002) and Tiwari et al. (2006) who found that buffalo owners in the smallholder buffalo farms also did not cut and disinfect the naval cord of the calves due to lack of knowledge about the navel care. Naval cord is a passage through which microorganisms can enter into the blood or underlying tissues leading navel ill and later joint ill in newly born calves. Therefore, it is very essential that the buffalo owners should take proper care of the naval cord immediately after birth of calves. Sharma and Mishra (1987) recommended cutting the cord with a sterile blade and then dipping the cord in a mild antiseptic solution. Lack of navel care might be a cause of high prevalence of navel ill in calves in this study (Figure 2).

This study identifies poor deworming program of buffalo calves by the farmers (Table 3b). In $13.6 \%$ farms, calves were dewormed and remaining $86.4 \%$ farms did not deworm their calves $(\mathrm{p}<0.05)$. Unexpectedly, owners did not follow the recommended deworming schedule when they dewormed their calves. Buffalo farmers usually dewormed their calves in diseased conditions particularly when the calves were in anorectic condition or farmers observed worms in the feces. Many other researchers also reported that the buffalo owners did not deworm their calves timely due to which the health condition of the calves was poor in the smallholder buffalo production system (Farook et al., 1999, Singh and Singh, 2000 and Das, 2001). Deworming in calves is essential and regular deworming cycle should be followed against parasitic infections. This practice should be started on or before two weeks of age, followed after 21 days and should be repeated three to four times in a year at regular interval (Tiwari et al., 2007). A major reason of calf mortality is the parasitic load in the calves due to which their health deteriorates and the calf often dies (Sharma and Mishra, 1987). Poor deworming practice by farmers might have led to highest prevalence of helminthiasis in this present study (Figure 2).

The vaccination practice in buffalo calves is shown in table 3(c). In $88.6 \%$ farms, calves were not vaccinated against any infectious diseases and calves of rest $11.4 \%$ farms were vaccinated against anthrax and foot and mouth disease $(\mathrm{p}<0.05)$. The result is in agreement with the finding of Mustufa et al. (2009) who reported that $100.0 \%$ smallholder buffalo farmers did not vaccinate their calves against any disease.

Table 3(d) indicates that majority of the dairy owners did not provide proper medication to the calves which is very much important particularly in neonatal period. In this study, significantly higher number of buffalo farms $(59.3 \%)$ treated sick calves by buffalo owner themselves and if not cured then called veterinarian 
$(\mathrm{p}<0.05)$. Sick calves were treated by registered veterinarian only in $12.9 \%$ farms and by quack (veterinary compounder) in $27.8 \%$ farms. Similar to our result, Tiwary et al. (2007) reported that $64.4 \%$ farmers treated their sick calves by themselves in Uttar Pradesh of India.

\section{Management practices of buffalo calves}

Colostrum was fed timely that means soon after birth in significantly $(\mathrm{p}<0.05)$ lower number $(4.3 \%)$ of farms (Table 4(a)). Calves were not allowed to feed colostrum in high percentage $(42.9 \%)$ of buffalo farms. Moreover, colostrum was fed after release of placenta (after 12 hours of parturition) in $52.8 \%$ farms. Results revealed that buffalo farmers did not feed the colostrum and even in wrong time when fed. Several authors have reported the similar results (Verma and Sastry, 1994; Malik and Nagpaul, 1999; Singh et al., 2003; Tiwari et al., 2007). They reported that buffalo owners feed colostrum to calves only after release of placenta with the belief that immediate colostrum feeding leads to problem in release of the placenta. Moreover, Kumar (2002) reported that farmers did not feed colostrum as they thought that colostrum feeding may lead to diarrhoea in calves. It is the most crucial period when calves should receive colostrum immediately after birth. Colostrum should be fed within two to three hours after birth because delay in feeding of colostrum lead to lowered effectiveness of the colostrum in terms of providing immunity to calves (Sharma and Mishra, 1987).

This study revealed that milk was fed to calves before and after milking in significantly higher number $(90.7 \%)$ of farms $(\mathrm{p}<0.05)$. Farmers left one teat full for calves in few farms (3.5\%) and half teat in 5.8\% farms (Table 4(b)). Similar to this present study, Tiwari et al. (2007) observed that $97.8 \%$ farmers provided the milk to the calves before and after milking only. Milk is more or less a complete food for young calf, to which gastrointestinal system is adopted for digestion of nutrients present in it. It has been emphasized that a calf must receive sufficient milk during first three months or a minimum of 110 liters of whole milk to be fed over a period of four to five weeks, along with a calf starter having a good quality protein and low fiber content (Sharma and Mishra, 1987). In our study, the calves were used only to stimulate milk let down and not for providing the milk to them. Even, after milking, farmers did not leave enough milk in the udder required for the survival of the calf. Inadequate milk supply to calves could be a cause of high prevalence of malnutrition in these farms (Figure 2).

The housing condition for calves is important for optimum health. Calves were kept in the corner of shed in $85.7 \%$ farms and without any bedding material in $55.0 \%$ farms. Individual space for calf was provided in $5.7 \%$ farms. Straw as bedding material was provided in $45.0 \%$ farms (Table 4(d)). The finding is supported by result of Tiwari et al. (2007) who reported that majority of the dairy owners $(92.2 \%)$ neither had a separate shed for the calves nor provided any bedding material (70.0\%). The housing conditions of the livestock greatly affects their health and productive 
performance specially the calves which are more prone to diseases as their immunity level is low. Furthermore, exposure to extreme climatic variations such as extreme heat and extreme cold leads to physical stress and the body of calves is not adapted to bear such stress and the calves may collapse (Tiwari et al. 2007).

\section{Mortality of buffalo calf}

Table 5 shows the mortality rate of buffalo calves. During the period from July 2010 to June 2011, a total of 482 buffalo calves were born of which 70 died (14.5\%). Mortality rate was higher (10.8\%) during first three months age of the calves compared with other age groups. However, mortality rate did not vary according to sex of the calves and seasons, which is in agreement with the finding of Khan et al. (2007). On the other hand, mortality number of the buffalo calves was significantly affected by total buffalo population in the farms $\left(\mathrm{R}^{2}=0.938, \mathrm{p}<0.001\right)$ (Figure 1). This could be due to farmers were not able to manage and care calves because of difficulties in maintaining large number of buffaloes in large farms. Calf mortality in our study is lower than that of Khan et al. (2007) who recorded $17.98 \%$ mortality in buffalo calves but similar to our finding they reported that calf mortality rate was higher during the first three months of age, while lower at the age group of three months and above. Moreover, Maousami et al. (2013) reported 22.48\% buffalo calf mortality at Bareilly and Surguja districts of Uttar Pradesh in India. The variation of calf mortality might be due to different buffalo breeds and management system adopted by the local farmers. However, improper colostrum feeding, lack of navel care, inappropriate deworming plan, inadequate vaccination practice and above all treatment of ill calves by buffalo owner themselves or quack could be a cause of calf mortality of $14.5 \%$ in the buffalo farms in this present study.

\section{Prevalence of buffalo calf diseases}

The frequency of occurrence of general disease and disease conditions of buffalo calves is presented in figure 2 . The helminthiasis $(20.3 \%)$ was identified as most prevalent disease in buffalo calves followed by malnutrition (13.2\%), indigestion (12.4\%) and navel ill $(9.3 \%)$. The prevalence of metabolic disorder, diarrhoea, anorexia, and eye diseases were $7.8 \%, 5.7 \%, 5.3 \% \%$ and $3.4 \%$, respectively. Pneumonia and ectoparasitic infestations both had $4.5 \%$ prevalence rate. Tiwari et al. (2006) reported the most common and frequent occurring disease in buffalo calves was diarrhoea $(82.2 \%)$ followed by endoparasite infestation $(80.0 \%)$, ectoparasite infestation (78.9\%), naval ill (66.7\%) and pneumonia (26.7\%). The variation on pattern of disease occurrence could be due to variation of buffalo breeds, season and geographical location of the study and management system of the farms.

\section{CONCLUSION}

The results of the present study concluded that health care and management practices of calves in dairy farms is highly neglected and pattern of calf rearing is almost similar in four districts of southern region of Bangladesh. Buffalo farmers 
need proper education, training and extension works about scientific management of calf health care and husbandry practice to ensure the best quality of germplasm of buffalo for the sustainable dairy development of Bangladesh.

\section{ACKNOWLEDGEMENTS}

We are thankful to Postgraduate Studies and Research (PGSR) of Patuakhali Science and Technology University, Dumki, Patuakhali, Bangladesh for financial support (Grant No. PGS-PSTU-06). Sincere gratitude is also extended to the buffalo farmers for their cooperation.

\section{REFERENCES}

Das, S. 2001. Small scale buffalo production systems and their sustainability: A case analysis. M.V. Sc. Thesis. Indian Veterinary Research Institute, Izatnagar, India

Farooq, M. K., Abdul, Q. and Qudoos, A. 1999. Constraints in the adoption of modern livestock practices. Pakistan Veterinary Journal, 19: 53-55

Khan, Z. U., Khan, S., Ahmad, N. and Raziq, A. 2007. Investigation of mortality incidence and managemental practices in buffalo calves at commercial dairy farms in Peshawar city. Journal of Agricultural and Biological Science, 2: 16-22

Kumar, S. 2002. Livestock production system of the resources poor in Mirzapur District (U.P.). M.V.Sc. Thesis. Indian Veterinary Research Institute, Izatnagar, India

Malik, D. S. and Nagpaul, P. K. 1999. Studies on milking and calf rearing management practices of Murrah buffalo in its home tract of Haryana. Indian Journal of Animal Production and Management, 15: 52-54

Maousami, B. P., Singh, R., Kumar, V. and Dohare, A. 2013. Analysis of buffalo calf management practices followed by buffalo owners. Journal of Animal Science Advances, 3: 129-133

Matondi, G. H. M., Nyamushamba, G. B., Motsi, T. T. and Masama, E. 2014. Evaluation of smallholder dairy calf rearing systems in Zimbabwe. Livestock Research for Rural Development, 26 (3)

Mustafa, M. Y., Younus, M., Saleem, K. and Mehmood, B. 2009. Management practices and health care of buffalo calf in District Sheikhupura: a field study. International Journal of Advanced Veterinary Medical Science, 3: 25-30

Osmani, M. G. 2012. Vision 2021: Role of veterinarian in Bangladesh. Bangladesh Veterinarians' Directory, pp 90-103

Shamsuddin, M., Goodger, W. J., Hossein, M. S., Bennett, A. T. and Nordlund, K. 2006. A survey to identify economic opportunities for smallholder dairy farms in Bangladesh. Tropical Animal Health Production, 38: 131-40

Sharma, M. C. and Mishra, R. R.1987. Livestock health and management. Khanna Publishers, New Delhi 
Singh, B. P., Tiwari, R. and Arya, H. P. S. 2003. Technology adoption behaviour of buffalo owners- A participatory study. In proceedings of the $4^{\text {th }}$ Asian buffalo congress, held at New Delhi during 25-28 Feb, 59

Singh, R. and Singh, N. 2000. Influence of socio-economic variables on adoption of buffalo calf rearing management practices in rural Haryana. Indian Journal of Animal Sciences, 70: 325-326

Talukder, A. K., Bhattacharjee, J., Rahman, M. B. and Shamsuddin, M. Shamsuddin. 2008. A community-based productivity veterinary service to smallholder dairy farmers in Mymensingh. In proceedings of Fourteenth Annual Scientific Conference, Bangladesh Society for Veterinary Education and Research, 33: 35

Tiwari, R., Singh, B. P. and Arya, H. P. S. 2003. Buffalo rearing practices in small farms: Few case studies. In proceedings of the 4th Asian Buffalo Congress, held at New Delhi during 25-28 Feb: 67

Tiwari, R., Sharma, M. C. and Singh, B. P. 2006. Studies on buffalo health and production practices in small farms. Indian Journal of Veterinary Medicine, 26: 62-64

Tiwari, R., Sharma, M. C. and Singh, B. P. 2007. Buffalo calf health care in commercial dairy farms: a field study in Uttar Pradesh (India). Livestock Research for Rural Development, 19 (3)

Verma, A. K. and Sastry, N. S. R. 1994. Milking management of Murrah buffaloes followed in rural India. In proceedings of the 4th world buffalo congress, held at Sao Paulo, Brazil, Volume 2 
Table 1. Buffalo population in four districts of southern region of Bangladesh. Number of farms $=35$ in each District

\begin{tabular}{|l|l|l|l|}
\hline Name of District & No. of buffaloes & $\begin{array}{l}\text { No. of lactating } \\
\text { cows }\end{array}$ & No. of calves \\
\hline Barisal & $48.5(20 \sim 100)$ & $18.4(5 \sim 40)$ & $15.7(5 \sim 35)$ \\
Patuakhali & $38.9(8 \sim 123)$ & $13.7(3 \sim 37)$ & $11.7(3 \sim 32)$ \\
Bhola & $22.9(8 \sim 80)$ & $6.7(3 \sim 25)$ & $5.7(2 \sim 20)$ \\
Jhalokati & $12.2(2 \sim 70)$ & $3.3(1 \sim 14)$ & $3.2(1 \sim 10)$ \\
\hline
\end{tabular}

Table 2. General health condition of buffalo calves in farms. Number of farms $=35$ in each District

\begin{tabular}{lcc|c|c|c|c|}
\hline Condition of calves & Barisal & Patuakhali & Bhola & Jhalokati & Total \\
\hline \multicolumn{5}{c}{ Number of farms (\%) } \\
Good & $4(11.4)$ & $5(14.2)$ & $5(14.2)$ & $7(20.0)$ & $21\left(15.0^{\mathrm{a}}\right)$ \\
Average & $18(51.4)$ & $15(42.9)$ & $16(45.8)$ & $21(60.0)$ & $70\left(50.0^{\mathrm{b}}\right)$ \\
Weak and emaciated & $13(37.2)$ & $15(42.9)$ & $14(40.0)$ & $7(20.0)$ & $49\left(35.0^{\mathrm{c}}\right)$ \\
Pooled & & & & 140 \\
\hline
\end{tabular}

Values having different superscripts $(a, b, c)$ within the same column are significantly different $(\mathrm{p}<0.05)$. 
Table 3 (a-d). Health care practices of calves in buffalo farms

\begin{tabular}{|l|c|c|c|c|c|}
\hline Type of health care & Barisal & Patuakhali & Bhola & Jhalokati & Total \\
\hline
\end{tabular}

Number of farms $(\%)$

(a) Navel care (cutting and disinfection) practice

$\begin{array}{lccccc}\begin{array}{l}\text { Cut and disinfect the navel } \\ \text { cord }\end{array} & 0(0.0) & 0(0.0) & 0(0.0) & 0(0.0) & 0(0.0) \\ \begin{array}{l}\text { Without navel care } \\ 35(100.0)\end{array} & 35(100.0) & 35(100.0) & 35(100.0) & 140100.0)\end{array}$

(b) Suitable deworming practices to calves

\begin{tabular}{|c|c|c|c|c|c|}
\hline $\begin{array}{l}\text { Dewormed the calves with } \\
\text { anthelmintics }\end{array}$ & 4 (11.4) & 4 (11.4) & $6(17.1)$ & $5(14.3)$ & $19\left(13.6^{\mathrm{a}}\right)$ \\
\hline Did not deworm & 31 (88.6) & $31(88.6)$ & $29(82.9)$ & $30(85.7)$ & $121\left(86.4^{b}\right)$ \\
\hline
\end{tabular}

(c) Vaccination to calves

$\begin{array}{lccccc}\text { Vaccinated the calves } & 3(8.6) & 2(5.7) & 5(14.3) & 6(17.1) & 16\left(11.4^{\mathrm{a}}\right) \\ \text { Did not apply vaccination } & 32(91.4) & 33(94.3) & 30(85.7) & 29(82.9) & 124\left(88.6^{\mathrm{b}}\right)\end{array}$
to the calves

(d) Types of treatment applied to treat sick calves

$\begin{array}{lccccc}\text { Called a veterinarian } & 3(8.6) & 3(8.6) & 6(17.1) & 6(17.1) & 18\left(12.9^{\mathrm{a}}\right) \\ \text { Called a quack } & 12(34.3) & 9(25.7) & 6(17.1) & 12(34.3) & 39\left(27.8^{\mathrm{b}}\right) \\ \begin{array}{l}\text { Self medication and if not } \\ \text { cured called a veterinarian }\end{array} & 20(57.1) & 23(65.7) & 23(65.8) & 17(48.6) & 83\left(59.3^{\mathrm{c}}\right)\end{array}$

Values having different superscripts $(a, b, c)$ within the same column in a group are significantly different $(\mathrm{p}<0.05)$. 
Table 4 (a-d). Calf rearing management practices in buffalo farms

\begin{tabular}{|l|l|l|l|l|l|}
\hline $\begin{array}{l}\text { Category of management } \\
\text { practice }\end{array}$ & Barisal & Patuakhali & Jhalokati & Bhola & Total (\%) \\
\hline
\end{tabular}

Number of farms $(\%)$

(a) Time of first colostrums feeding

$\begin{array}{lccccc}\text { Soon after birth } & 2(5.7) & 1(2.8) & 1(2.8) & 2(5.7) & 6\left(4.3^{\mathrm{a}}\right) \\ \text { After release of placenta } & 20(57.1) & 16(45.7) & 19(54.3) & 19(54.3) & 76\left(58.8^{\mathrm{b}}\right) \\ \text { Did not feed colostrum } & 13(37.2) & 18(51.5) & 15(42.9) & 14(40.0) & 58\left(42.9^{\mathrm{b}}\right)\end{array}$

(b) Milk feeding management of calves

$\begin{array}{lccccr}\text { Left one teat full } & 1(2.8) & 1(2.8) & 2(5.7) & 1(2.8) & 5\left(3.5^{\mathrm{a}}\right) \\ \text { Half-teat devoted } & 3(8.6) & 2(5.7) & 1(2.8) & 2(5.7) & 8\left(5.8^{\mathrm{a}}\right) \\ \text { Before and after milking } & 31(88.6) & 32(91.5) & 32(91.5) & 32(91.5) & 127\left(90.7^{\mathrm{b}}\right)\end{array}$

(c) Housing system for buffalo calves

$\begin{array}{lccccr}\text { Individual space allotment } & 2(5.7) & 3(8.6) & 1(2.8) & 2(5.7) & 8\left(5.7^{\mathrm{a}}\right) \\ \begin{array}{l}\text { Calves kept together in calf } \\ \text { pen }\end{array} & 2(5.7) & 2(5.7) & 5(14.3) & 3(8.6) & 12\left(8.6^{\mathrm{a}}\right) \\ \begin{array}{l}\text { Calf tied in the corner of } \\ \text { shed }\end{array} & 31(88.6) & 30(85.7) & 29(82.9) & 30(85.7) & 120\left(85.7^{\mathrm{b}}\right)\end{array}$

(d) Bedding practices for buffalo calves

$\begin{array}{llllll}\text { Provided bedding materials } & 13(37.1) & 15(42.9) & 17(48.6) & 18(51.4) & 63(45.0) \\ \text { Without bedding for calves } & 22(62.9) & 20(57.1) & 18(51.4) & 17(48.6) & 77(55.0)\end{array}$

Values having different superscripts $(\mathrm{a}, \mathrm{b})$ within the same column in a group are significantly different $(\mathrm{p}<0.05)$. 
Table 5. Mortality of buffalo calves during the period from July 2010 to June 2011. Number of calves born $=482$

\begin{tabular}{|l|l|l|}
\hline Factors & No. of calves died & Mortality rate (\%) \\
\hline
\end{tabular}

(a) Effect of age (month) on calf mortality

$\begin{array}{lcc}1-3 & 52 & 10.8 \\ 4-6 & 13 & 2.7 \\ >6-12 & 5 & 1.0 \\ \text { Pooled } & 70 & 14.5\end{array}$

(b) Effect of sex on calf mortality

Male 38

$38 \quad 7.9$

Female

32

6.6

(c) Effect of season on calf mortality

Summer

Autumn 


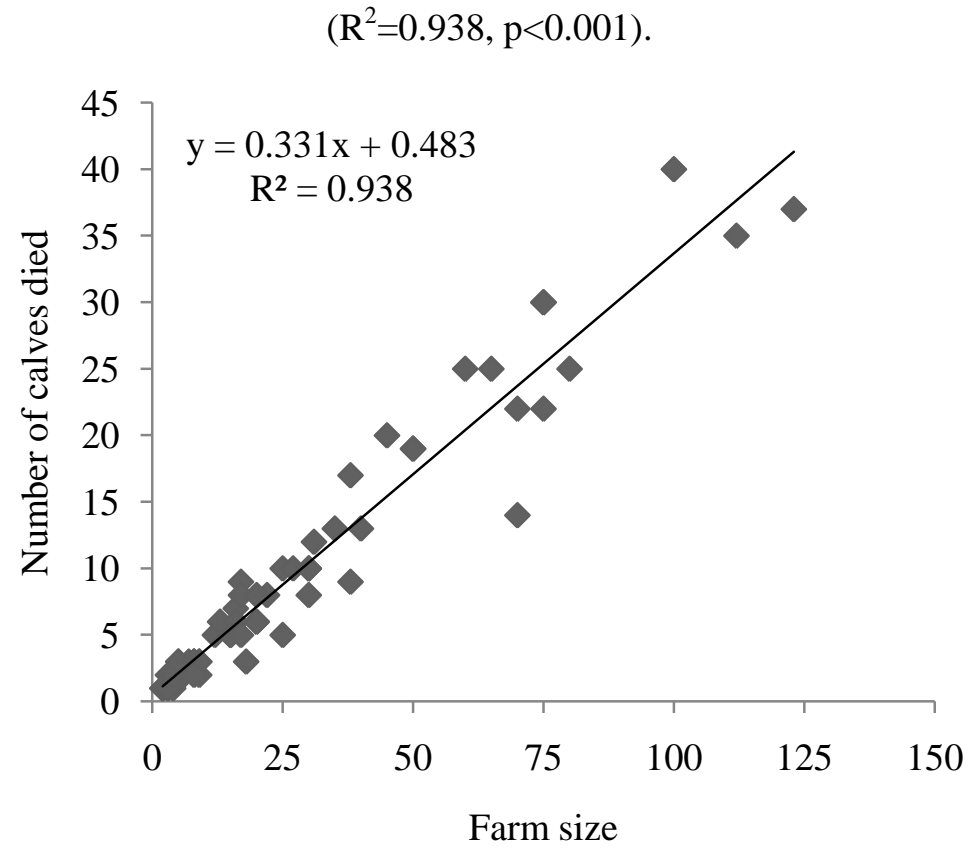

Figure 1. Relationship between number of calves died (absolute calf mortality) in the farms and farm size.

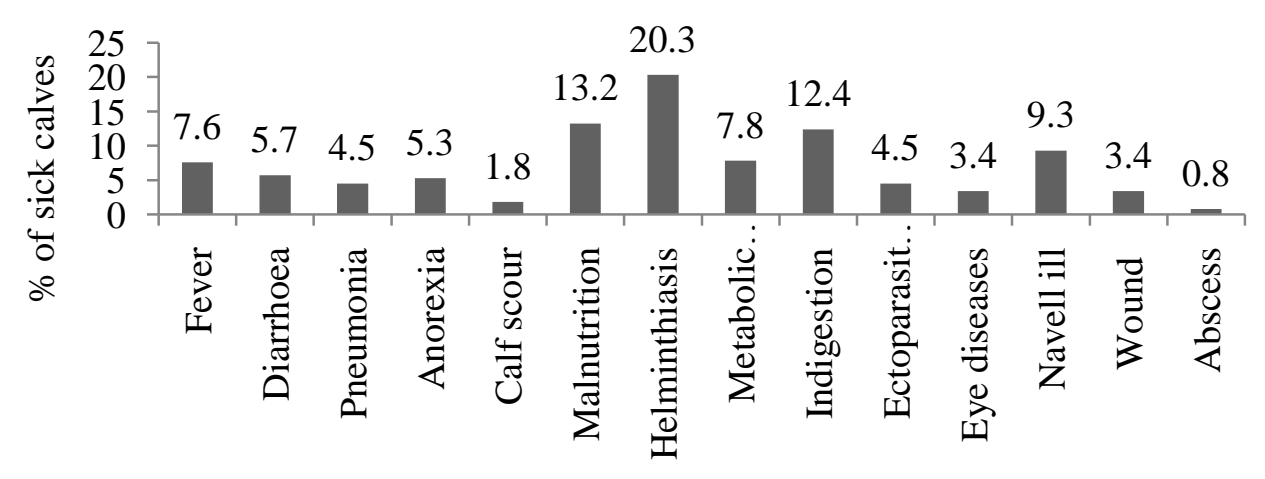

General disease and disease conditions

Figure 2. Frequency of general disease and disease conditions of buffalo calves. Total number of buffalo calves $=236$. 